\title{
ESTRATÉGIAS PARA O FOMENTO DO COOPERATIVISMO ESTUDANTIL NA UFFS CAMPUS CHAPECÓ/SC
}

\section{STRATEGIES FOR THE PROMOTION OF STUDENT COOPERATIVISM IN UFFS CHAPECÓ/SC CAMPUS STUDENTS}

\author{
Franco Apolo Ruver ${ }^{1}$ \\ ORCID: https://orcid.org/0000-0002-2104-5545
}

Submissão: 06/05/2020 / Aceito: 22/09/2020.

\begin{abstract}
Resumo
Este estudo visa propor estratégias para fomentar o cooperativismo estudantil na UFFS Campus Chapecó. Para que o objetivo fosse alcançado, realizaram-se entrevistas com representantes de seis cooperativas estudantis dos estados de Santa Catarina e Rio Grande do Sul, a realização de uma pesquisa com os estudantes da UFFS, com vistas a compreender o seu perfil, a sua percepção quanto ao cooperativismo e a sua predisposição ao cooperativismo. O estudo é de natureza qualitativa, classificada quanto aos fins como descritiva e quanto aos meios como estudo de campo. Como resultados da pesquisa, observa-se, que para a viabilização e consolidação de uma cooperativa de estudantes na UFFS Campus Chapecó, tornam-se necessárias a tomada de algumas medidas propostas em um plano de ações, como por exemplo, gerar conhecimento sobre cooperativismo entre os estudantes da universidade, definir o ramo de atuação da cooperativa, suas principais atividades e benefícios aos associados e o processo de constituição da cooperativa.
\end{abstract}

Palavras-chave: Cooperativismo Estudantil; Constituição de cooperativas; Plano de Ação.

\begin{abstract}
This study aims to propose strategies to foster cooperative in the UFFS Campus Chapecó. In order to achieve this objective, interviews with representatives of six student cooperatives in the states of Santa Catarina and Rio Grande do Sul were carried out, a survey was carried out with UFFS students, in order to understand their profile, their perception as well as their predisposition to cooperativism. The study is qualitative in nature, classified for purposes as descriptive and for means as a field study. As a result of the research, it is observed that for the feasibility and consolidation of a cooperative of students in the Campus Chapecó UFFS, it is necessary to take some measures proposed in a plan of actions, such as to generate knowledge about cooperativism in university, define the branch of activity of the cooperative, its main activities and benefits to the members and the process of constitution of the cooperative.
\end{abstract}

Keywords: Student Cooperativism, Constitution of cooperatives, Action plan.

\footnotetext{
${ }^{1}$ Bacharel em Administração pela Universidade Federal da Fronteira Sul (UFFS). E-mail: francoapruver@gmail.com
} 


\section{INTRODUÇÃO}

Parte-se do pressuposto de que uma empresa privada se trata de uma sociedade de capital e uma cooperativa uma sociedade de pessoas, sendo que os objetivos da primeira são voltados a expansão econômica dos sócios e da segunda a satisfação das necessidades dos associados. O capital social de uma empresa privada é integralizado por seus sócios, com as cooperativas o mesmo acontece, o diferencial é que para que uma cooperativa seja constituída, é necessário de no mínimo vinte pessoas para a formação do conselho de Administração. Uma cooperativa nasce de uma necessidade conjunta, na qual existe a vontade de viabilizar um empreendimento capaz de gerar retornos econômicos e sociais para os seus cooperados. Geralmente uma pessoa ou um pequeno grupo de pessoas não consegue viabilizar um determinado empreendimento, mas com a união e a cooperação de várias pessoas o empreendimento se viabiliza. Essa união, consequentemente, faz com que se reduzam os custos com investimentos, pois rateiam-se custos, fazendo com que, todos colham os frutos em conjunto, sem ter grande dispêndio de capital. Existem situações em que cooperativas surgem para favorecer comunidades inteiras, em cerca de 564 municípios brasileiros, as cooperativas de crédito são as únicas instituições financeiras locais, 807 municípios brasileiros são atendidos por cooperativas de eletrificação e $38 \%$ dos brasileiros são atendidos em cooperativas de saúde (SESCOOP/RS, 2017).

Cooperativas formadas por estudantes possuem os mais diversos objetivos, que podem vir a ser de produção, comercialização ou qualquer aplicação às necessidades sentidas pelos cooperados. Assim como destaca Andrioli (2007, p.43), “o cooperativismo pode oferecer elementos importantes para a educação, se considerarmos a cooperação como base da sociabilidade". É neste aspecto que se pode dizer que o cooperativismo e a educação são práticas sociais, e surgem como produtos sociais, decorrentes das necessidades humanas (ANDRIOLI, 2007). A relação principal existente entre educação e cooperação é o fato de ambas atenderem demandas sociais, principalmente geradas pela necessidade de relacionamento e construção cultural do ser humano.

Uma organização cooperativista formada, principalmente por estudantes, deve abrir espaços para a vivência da cooperação, ao invés do estímulo a competição (ANDRIOLI, 2007). Em sua obra, Andrioli (2007) conclui que as cooperativas escolares não visam lucros, são mais organizadas e são mais superficiais, o que favorece o princípio da autogestão, na qual os 
Revista Cadernos de Economia

Universidade Comunitária da Região de Chapecó - Unochapecó

próprios cooperados fazem a gestão da cooperativa. Ainda conforme Andrioli (2007), um dos grandes desafios e fatores limitadores desse tipo de cooperativa é a baixa participação e envolvimento dos alunos/cooperados quanto as questões da cooperativa. O objetivo geral é propor estratégias para fomentar o comportamento cooperativista para a constituição de uma cooperativa de estudantes na UFFS Campus Chapecó/SC.

\section{COOPERATIVISMO: ELEMENTOS CONSTITUINTES E GESTÃO}

\section{Cooperativismo}

Para embasar a discussão a respeito do conceito de cooperativa, a Lei nº 5.764 de 1971, conhecida como a lei das cooperativas, institui que, conforme o Art. $3^{\circ}$ desta constituição, "Celebram contrato de sociedade cooperativa as pessoas que reciprocamente se obrigam a contribuir com bens ou serviços para o exercício de uma atividade econômica, de proveito comum, sem objetivo de lucro". Também em seu Art. 4", "As cooperativas são sociedades de pessoas, com forma e natureza jurídica próprias, de natureza civil, não sujeitas a falência, constituídas para prestar serviços aos associados".

Como forma de diferenciar uma cooperativa de uma associação e de uma empresa privada, parte-se do pressuposto de que a cooperativa é um modelo híbrido entre uma associação e uma empresa, conforme visualizada na Figura 1. Dessa forma, a cooperativa é uma associação de pessoas e não de capitais com um objetivo de fortalecer o elo econômico dos associados. Neste sentido, a cooperativa funciona como uma empresa comum, mas com objetivo de complementar a administração das economias individuais, sempre com uma visão de coletividade, o coletivo em prol do individual (FRANTZ, 2012).

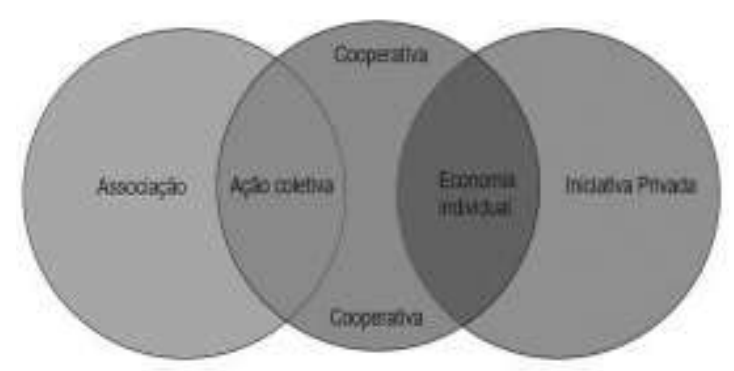

Figura 1 - Diferenciação entre cooperativas e outros tipos de empreendimentos Fonte: Elaborado pelo autor, 2017. 


\title{
Aspectos primordiais a cooperação
}

A cooperação é um processo complexo, na visão de Lehmann e Keller (2006 apud LAGO; SILVA, 2011, p. 32), a cooperação só pode evoluir sob a existência de benefício direto ao exercer a cooperação, e/ou interações constantes através do conhecimento prévio do sócio, e/ou sob interações de parentesco entre os indivíduos. Neste contexto, as "manifestações de auxílio mútuo surgem, geralmente, em períodos sociais mais adversos ao atendimento das necessidades coletivas" (ARAÚJO, 1982 apud LAGO; SILVA, 2011, p. 34).

A cooperação se demonstra de diversas formas, é o que apresentam Khamis; Kamel e Salichs (2007 apud LAGO; SILVA, 2011, p. 35), primeiro a cooperação se apresenta como Stimergy, um termo da biologia que descreve a influência no comportamento por meio de um efeito do comportamento prévio de um ambiente, como é o caso dos feromônios ${ }^{2}$. A cooperação se apresenta também como comunicação, coordenação, na qual se trata da interdependência entre entidades cooperativas para atingir metas. Outra forma é através do altruísmo, baseado na solidariedade; reciprocidade como dependência mútua; condicionalidade, na busca de ganhos mútuos e outros padrões como racionalidade, intencionalidade, intelectualidade e reatividade.

Um empreendimento solidário como é o caso das cooperativas, proporcionam a experiência do resgate do humano a vida social.

\begin{abstract}
A organização de um empreendimento solidário, ao tirar o indivíduo de seu mundo particular, relacionando-o com os outros, pelos laços sociais da amizade, da emoção, da razão, da associação, da cooperação, construindo espaços coletivos, desperta a responsabilidade social e a solidariedade, elementos fundamentais ao desenvolvimento do ser humano e de seus espaços de vida. Os seres humanos se humanizam pelo reconhecimento solidário e cooperativo do outro (FRANZ, 2012, p.26).
\end{abstract}

\section{Autogestão}

A autogestão, além de ser uma das características mais predominantes das organizações cooperativistas e de economia solidária, é também uma das formas de se diferenciar organizações cooperativistas de empresas privadas praticantes da heterogestão. Neste sentido, a autogestão é uma iniciativa na qual seus participantes detêm a posse coletiva dos meios de

\footnotetext{
${ }^{2}$ São substâncias químicas produzidas por um ser, que possuem finalidade de atrair outro para uma ação.
} 
produção inerentes a atividade da cooperativa, e por isso são igualmente responsáveis pelo gerenciamento do empreendimento pelo princípio de que um membro é igual a um voto (AZAMBUJA, 2009).

É neste contexto que Azambuja (2009, p. 12) salienta as principais características de uma organização autogestionária:

\begin{abstract}
posse coletiva dos meios pelos quais os indivíduos exercem a atividade econômica (produção, poupança, serviços, etc.); gestão democrática e igualitária do empreendimento através do princípio 'um membro igual a um voto' e, sendo, assim, o órgão máximo de decisões é a assembleia geral; divisão dos ganhos e perdas financeiras da empresa de forma igualitária ou por critérios acordados pelo coletivo, e recusa ao assalariamento permanente.
\end{abstract}

A autogestão é em si, a soma de práticas e saberes orientados por princípios e valores ${ }^{3}$, que visam o desenvolvimento humano, estabelecendo condições e práticas capazes de transformar a consciência e o comportamento dos seus praticantes (AZAMBUJA, 2009).

\title{
Gestão de cooperativas
}

O modelo de gestão composto pela estrutura organizacional da cooperativa, de acordo com Reisdorfer (2014, p.51) tem como objetivo "permitir que os associados possam apresentar seus problemas e necessidades". Por meio de análises os executivos e associados podem definir ou redefinir os objetivos e metas da cooperativa para que os serviços por ela prestados tragam valor aos associados, e também, tem a mesma função para os recursos nela alocados, com o propósito de eficiência nas suas relações sociais e mercadológicas.

Dessa forma, destaca-se a complexidade e a necessidade de um modelo de gestão altamente eficiente nas cooperativas, tomando por base que a gestão de uma cooperativa se assemelha ao de uma empresa privada em alguns aspectos operacionais, devendo contemplar também, todos os aspectos inerentes aos princípios cooperativistas e também ao próprio princípio de autogestão. Neste sentido, torna-se necessário a análise do seguinte fator: o cooperativismo adota uma importância social significativa, mas as cooperativas necessitam ser igualmente eficientes sob a ótica do ponto de vista econômico, "quanto maior for a eficiência econômica da cooperativa, tanto maior será também, seu alcance social e de desenvolvimento" (BIALOSKORSKI NETO, 2012, p. 20).

\footnotetext{
${ }^{3}$ Solidariedade, igualdade, cooperação, autonomia, participação, democracia, viabilidade econômica, etc.
} 
Nessa linha de pensamento, Bialoskorski Neto (2012) ainda destaca que "não há lugar no sistema produtivo para organizações incompetentes, que aplicam mal os recursos produtivos da sociedade, lesam o meio ambiente e não geram resultado e bem-estar". O autor ainda cita que as organizações cooperativas não devem limitar-se apenas a ação social, desprezando a sua planta produtiva, e que, o caso de sua ruptura por desleixo, implica em custos sociais elevados a seu quadro social.

\section{Metodologia}

Quanto a sua abordagem, o estudo caracteriza-se por ser qualitativa. Utilizou-se também o método de entrevista semiestruturada para o levantamento de dados primários. Quanto aos seus objetivos, esta pesquisa se apresenta como descritiva.

Para o alcance dos objetivos da pesquisa, realizou-se uma série de seis entrevistas com cooperativas estudantis dos estados de Santa Catarina e Rio Grande do Sul. Neste aspecto, utilizou-se de um método de amostragem não probabilística, denominada como amostragem intencional por conveniência. Quanto ao questionário difundido aos estudantes por e-mail, obteve-se 269 questionários, veiculados durante um período de 30 dias. Amostra essa que corresponde a aproximadamente $10 \%$ da população presente na universidade.

O processo metodológico é mais bem evidenciado na Figura 2.

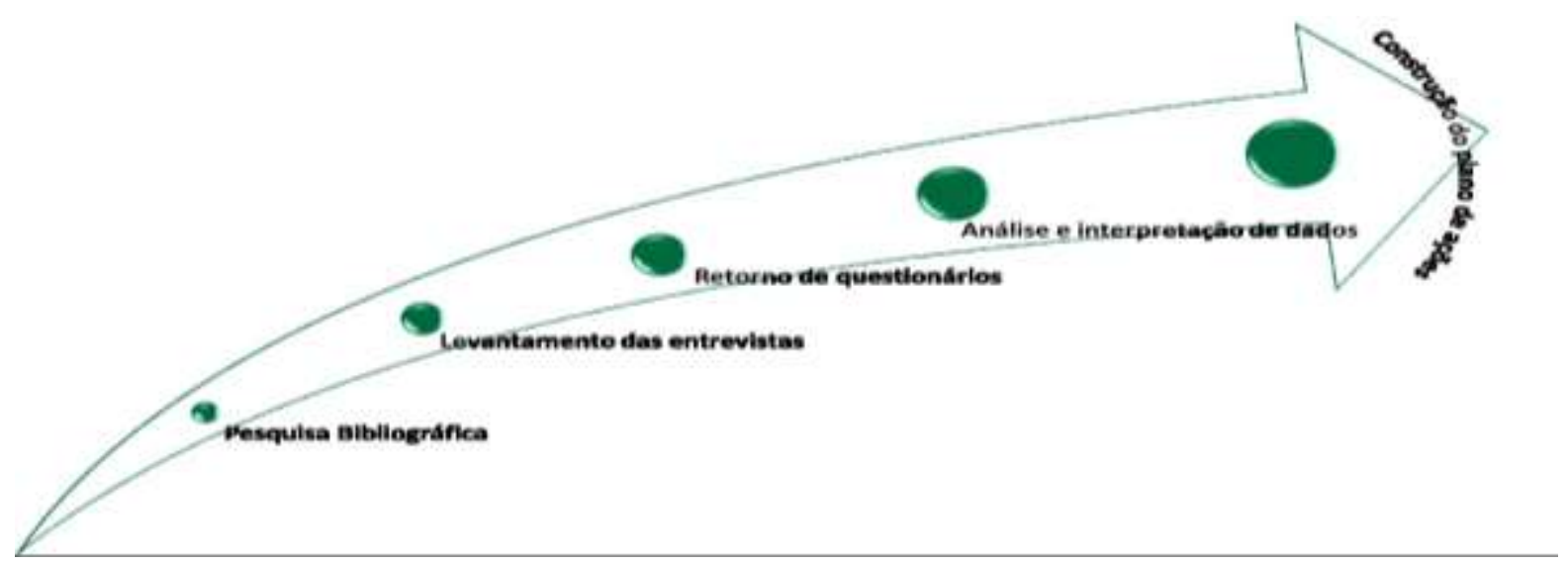

Figura 2 - Processo coleta de dados

Fonte: Elaborado pelo autor, 2018. 
Nesta perspectiva, buscou-se por meio de um questionário obter os dados necessários para identificar o perfil dos estudantes, a sua percepção e conhecimento sobre o cooperativismo e a sua predisposição para cooperar. O questionário veiculado durantes os dias 23 de abril de 2018 a 23 de maio de 2018, caracteriza-se por ser do tipo fechado, na qual, de acordo com Severino (2007), as questões devem ser objetivas, buscando respostas igualmente objetivas, neste caso, as respostas são escolhidas através das opções predefinidas pelo pesquisador. $\mathrm{O}$ questionário também contou com uma questão aberta que possibilitou aos alunos expressarem suas opiniões a respeito do cooperativismo.

A primeira etapa da pesquisa, trata-se de uma pesquisa qualitativa, da qual, possui as suas ferramentas de coleta de dados. Neste caso, optou-se pela análise de conteúdo, sendo uma técnica que busca objetividade, sistematização e inferência. Dessa forma, a análise de conteúdo "inicia pela leitura das falas, realizada por meio das transcrições de entrevistas, depoimentos e documentos" (MINAYO, 2007 apud GERHARDT; SILVEIRA, 2009, p. 85).

Para que se possa constituir e consolidar uma cooperativa estudantil, propõem-se neste trabalho, criar um plano de ações que servirá como norteador das decisões a serem tomadas, com base nas experiências cooperativistas já estabelecias e na pesquisa realizada com os estudantes. Para isso, apresenta-se no Quadro 1 um modelo de plano de ações chamado 5W2H, contemplando os norteadores estratégicos necessários para a criação de uma cooperativa estudantil, no atual contexto vivido pelos estudantes.

\begin{tabular}{|c|c|c|c|c|c|c|}
\hline \multicolumn{7}{|c|}{ PLANO DE AÇÃO } \\
\hline \multicolumn{5}{|c|}{$5 W$} & \multicolumn{2}{|r|}{$2 \mathrm{H}$} \\
\hline WHAT & WHO & WHERE & WHEN & $W H Y$ & HOW & HOW MUCH \\
\hline O QUE? & QUEM? & ONDE? & QUANDO? & POR QUÊ? & COMO? & QUANTO CUSTA? \\
\hline $\begin{array}{l}\text { Que ação } \\
\text { será } \\
\text { executada? }\end{array}$ & $\begin{array}{c}\text { Quem está } \\
\text { envolvido na } \\
\text { ação? }\end{array}$ & $\begin{array}{l}\text { Onde será } \\
\text { executada } \\
\text { a ação? }\end{array}$ & $\begin{array}{l}\text { Quando a } \\
\text { ação será } \\
\text { executada? }\end{array}$ & $\begin{array}{c}\text { Por que a ação } \\
\text { será } \\
\text { executada? }\end{array}$ & $\begin{array}{c}\text { Como será } \\
\text { executada } \\
\text { a ação? }\end{array}$ & $\begin{array}{l}\text { Quanto custa para } \\
\text { executar a ação? }\end{array}$ \\
\hline
\end{tabular}

Quadro 01 - Ferramenta 5W2H

Fonte: Adaptado de Meira (2003, apud SILVA et al., 2013, p. 03).

A ferramenta serve como um norteador para as decisões a serem tomadas por um possível grupo fundador de uma cooperativa de estudantes, podendo o mesmo ser revisto e 
Revista Cadernos de Economia

Universidade Comunitária da Região de Chapecó - Unochapecó

adaptado às necessidades, desde que, os apontamentos realizados não sejam desconsiderados, pois provém de experiências anteriores e da consulta aos estudantes do Campus.

O plano de ações foi construído com base nas experiências pessoais do autor, nas entrevistas com as cooperativas estudantis e na pesquisa com os acadêmicos da UFFS Campus Chapecó. Neste sentido a Figura 3 representa os pilares para a construção do plano de ações.

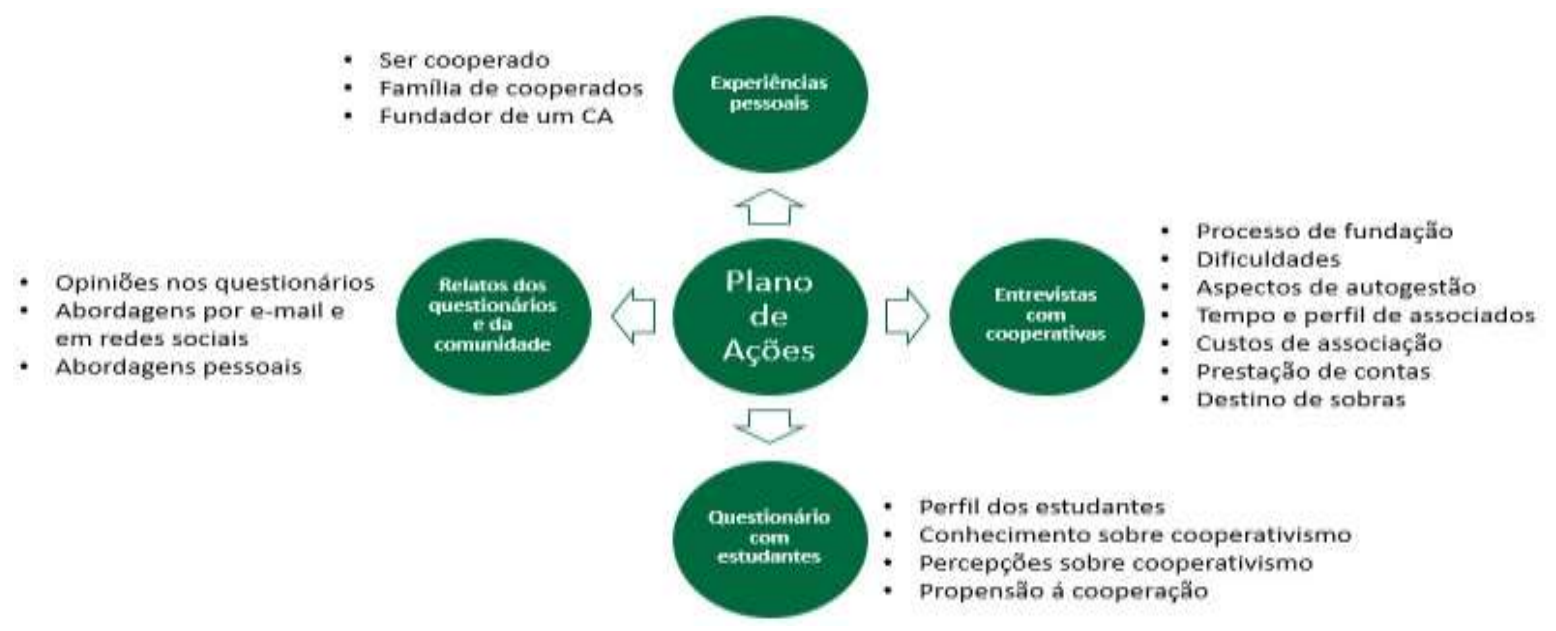

Figura 3 - Pilares para a construção do plano de ações

Fonte: Elaborado pelo autor (2018).

\section{RESULTADOS}

\section{Mapeamento de experiências com cooperativas estudantis}

Com vistas a resumir as entrevistas realizadas com os principais agentes das cooperativas, e a traçar uma visão geral das cooperativas estudantis, elaborou-se o Quadro 02. Dessa forma, torna-se possível tecer alguns comparativos entre as cooperativas estudadas, possibilitando que o caso prático dessas cooperativas sirva de exemplo para a constituição de demais cooperativas estudantis. 
Revista Cadernos de Economia

Universidade Comunitária da Região de Chapecó - Unochapecó

\begin{tabular}{|c|c|c|c|c|c|c|}
\hline Características & Cooperativa 1 & Cooperativa 2 & Cooperativa 3 & Cooperativa 4 & Cooperativa 5 & Cooperativa 6 \\
\hline Fundação & 1984 & 2001 & 2001 & 1987 & 2010 & 1979 \\
\hline Entrevistado & Vice-Presidente & Professor Orientador & Professor Orientador & Presidente & Presidente & Gerente \\
\hline $\begin{array}{l}\text { Motivo da } \\
\text { constituição }\end{array}$ & $\begin{array}{c}\text { Insustentabilidade do } \\
\text { colégio agricola por } \\
\text { parte do estado. }\end{array}$ & $\begin{array}{c}\text { Insustentabilidade do } \\
\text { colégio agrícola por } \\
\text { parte do estado. }\end{array}$ & $\begin{array}{c}\text { Insustentabilidade do } \\
\text { colégio agricola por } \\
\text { parte do estado. }\end{array}$ & $\begin{array}{l}\text { Comercialização } \\
\text { de produtos de } \\
\text { origem didática }\end{array}$ & $\begin{array}{l}\text { Incentivo de um } \\
\text { professor após uma } \\
\text { visita na Argentina }\end{array}$ & $\begin{array}{l}\text { Provar que o } \\
\text { cooperativismo } \\
\text { funciona }\end{array}$ \\
\hline Iniciativa & CEDUP & CEDUP & CEDUP & Alunos & Professor & Alunos \\
\hline Dificuldades & $\begin{array}{c}\text { Gestão de custos; } \\
\text { Ilegalidade perante o } \\
\text { CEDUP; }\end{array}$ & $\begin{array}{l}\text { Ilegalidade perante o } \\
\text { CEDUP; } \\
\text { Custos elevados; }\end{array}$ & $\begin{array}{c}\text { Formalização junto a } \\
\text { OCESC; }\end{array}$ & Não destacadas & $\begin{array}{l}\text { Provar aos alunos } \\
\text { que uma cooperativa } \\
\text { faz a diferença }\end{array}$ & $\begin{array}{l}\text { Liberação de crédito; } \\
\text { Imagem perante a } \\
\text { sociedade; } \\
\text { Ditadura militar; } \\
\text { Registro junto ao } \\
\text { INCRA }\end{array}$ \\
\hline Quadro social & Estudantes & Estudantes & Estudantes & Estudantes & Estudantes & Qualquer interessado \\
\hline Autogestão & $\begin{array}{l}\text { Alunos participam } \\
\text { de decisões; } \\
\text { Trazem sugestões; } \\
\text { Poderia haver maior } \\
\text { engajamento dos } \\
\text { alunos }\end{array}$ & $\begin{array}{l}\text { Os alunos aprendem } \\
\text { a parte burocrática; } \\
\text { As demandas são } \\
\text { repassadas aos } \\
\text { alunos; }\end{array}$ & $\begin{array}{c}\text { Cooperativa é gerida } \\
\text { pelos estudantes, mas } \\
\text { massa decisão final é } \\
\text { da gestão da escola. } \\
\text { Baixa participação } \\
\text { dos estudantes na } \\
\text { gestão }\end{array}$ & $\begin{array}{l}\text { Estudantes } \\
\text { gerenciam a } \\
\text { cooperativa }\end{array}$ & $\begin{array}{l}\text { A cooperativa possui } \\
\text { um orientador, mas } \\
\text { ao alunos que } \\
\text { gerenciam tudo, } \\
\text { desde o caixa ás } \\
\text { reuniões }\end{array}$ & $\begin{array}{c}\text { Participação doa } \\
\text { associados no dia a } \\
\text { dia; } \\
\text { Associados } \\
\text { trabalhavam na } \\
\text { cooperativa } \\
\text { voluntariamente }\end{array}$ \\
\hline $\begin{array}{l}\text { Duração da } \\
\text { gestão }\end{array}$ & $\begin{array}{c}\text { Um ano; Renovação } \\
1 / 3\end{array}$ & $\begin{array}{c}\text { Dois anos; } \\
\text { Renovação } 100 \% \text {. }\end{array}$ & Dois anos & Um ano & $\begin{array}{c}\text { Um ano, por } \\
\text { processo de sucessão }\end{array}$ & Dois anos \\
\hline $\begin{array}{l}\text { Custos de } \\
\text { associação }\end{array}$ & $\begin{array}{l}\text { Internos: R\$350,00; } \\
\text { Semi-internos: R\$ } \\
20,00 \\
\text { Externos: R\$ } 80,00 \text {. }\end{array}$ & $\begin{array}{c}\text { Cota capital de R\$ } \\
10,00 \text { mais ajuda de } \\
\text { custos mensais de: } \\
\text { Internos R\$ } 300,00 \\
\text { Semi-internos R\$ } \\
125,00\end{array}$ & $\begin{array}{c}\text { Cota capital de R\$ } 36 \\
\text { mais ajuda de custos } \\
\text { não divulgada }\end{array}$ & $\begin{array}{l}\text { Cota capital de } \\
\text { RS } 21,00\end{array}$ & $\begin{array}{c}\text { Cota capital de RS } \\
\qquad 4,00\end{array}$ & $\begin{array}{c}\text { Cota capital de } R \$ \\
70,00 \text { mais } R \$ 30,00 \\
\text { de joia }\end{array}$ \\
\hline $\begin{array}{l}\text { Tempo de } \\
\text { associação }\end{array}$ & $\begin{array}{l}\text { Permanência do } \\
\text { aluno no colégio }\end{array}$ & $\begin{array}{c}\text { Permanência do aluno } \\
\text { no colégio }\end{array}$ & $\begin{array}{c}\text { Permanência do aluno } \\
\text { no colégio }\end{array}$ & $\begin{array}{l}\text { Permanência do } \\
\text { aluno no colégio } \\
\text { mais um ano }\end{array}$ & $\begin{array}{l}\text { Permanência do } \\
\text { aluno no colégio }\end{array}$ & Indeterminado \\
\hline $\begin{array}{l}\text { Prestação de } \\
\text { contas }\end{array}$ & $\begin{array}{l}\text { Pré assembleia } \\
\text { assembleia geral }\end{array}$ & $\begin{array}{c}\text { Prestação de contas } \\
\text { mensais e assembleia } \\
\text { geral }\end{array}$ & $\begin{array}{c}\text { Em assembleia geral } \\
\text { ordinária }\end{array}$ & $\begin{array}{l}\text { Assembleia geral } \\
\text { ordinária }\end{array}$ & $\begin{array}{c}\text { Assembleia geral } \\
\text { ordinária }\end{array}$ & $\begin{array}{c}\text { Assembleia geral } \\
\text { ordinária }\end{array}$ \\
\hline $\begin{array}{l}\text { Destino de } \\
\text { sobras }\end{array}$ & Fundos de reserva & $\begin{array}{l}\text { Investimentos no } \\
\text { colégio }\end{array}$ & $\begin{array}{l}\text { São capitalizadas na } \\
\text { própria cooperativa }\end{array}$ & Fundos de reserva & Fundos de reserva & $\begin{array}{c}\text { Assistência técnica e } \\
\text { social e fundos de } \\
\text { reserva }\end{array}$ \\
\hline
\end{tabular}

Quadro 02 - Resumo das principais características das cooperativas

Fonte: Elaborado pelo autor, 2018.

Conforme apresentado no Quadro 02, ao se tratar do quadro social, as cooperativas apresentadas mantêm até hoje apenas estudantes como cooperados, com a exceção da Cooperativa 6, que devido ao seu porte e ramo de atuação, permite hoje que qualquer pessoa seja associada. Com relação aos aspectos de autogestão, percebe-se que existe o problema da baixa participação e interação dos associados na gestão das cooperativas, mas os associados buscam auxiliar com ideias ou sugestões pontuais. 
No que concerne ao período de cada gestão, as cooperativas não possuem uma unanimidade, sendo que $50 \%$ delas adotou em assembleia como tendo pleitos de um ano e os outros $50 \%$ como sendo de dois anos. Os custos de associação são variados, podendo ser uma contribuição única em forma de cota capital, como é o caso das cooperativas rio-grandenses ou com o pagamento de ajudas de custos mensais como é o caso das catarinenses que visam manter uma estrutura de internato e colégio agrícola. O tempo na qual o associado pode permanecer no quadro social é indeterminado apenas no caso da Cooperativa 6, nas demais cooperativas, o associado é desligado após a conclusão do seu curso, medida que se deve ao fato de que, quando o associado não tem mais vínculo com a instituição de ensino, a finalidade da cooperativa deixa de existir para aquele cooperado.

Como se pôde perceber, a prestação de contas das cooperativas segue o padrão de Assembleias Gerais Ordinárias e o investimento das sobras é na capitalização da própria cooperativa, principalmente em fundos de reserva, com vistas a expansão e consolidação da cooperativa ao longo do tempo.

O caso das cooperativas estudantis, apresentadas, reforçam a ideia de que todas as cooperativas possuem algum aspecto a melhorar, como é o caso da adesão livre e voluntária, da autonomia e independência, da autogestão e aspectos voltados a gestão da cooperativa. $\mathrm{O}$ fato indiscutivelmente, é que essas cooperativas possuem um papel muito mais importante do que apenas comercializar algo, ou sustentar alguma estrutura, os casos apresentados nos mostram o quanto uma cooperativa impacta na vida de milhares de pessoas.

Por meio da sua colaboração, milhares de estudantes dos CEDUPS, no caso catarinense, possuem uma estrutura privilegiada para a realização das suas atividades pedagógicas, assim como, no Rio Grande do Sul possibilitou-se a comercialização da produção dos alunos e o reconhecimento nacional de uma cooperativa estudantil bem estruturada.

As cooperativas apresentam alguns pontos em comum, mas as suas particularidades às tornam únicas. Como se pode perceber, os motivos e iniciativas para a constituição, são semelhantes apenas entre os CEDUPS de Santa Catarina, e que são completamente diferentes dos motivos e iniciativas que geraram a constituição das cooperativas do Rio Grande do Sul. Quanto às suas dificuldades para constituição e manutenção, percebe-se que aspectos jurídicos e de gestão são mais aparentes. 


\section{Resultados da pesquisa aplicada com estudantes da UFFS \\ Perfil do estudante da UFFS}

Ao consultar os acadêmicos da UFFS Campus Chapecó, pode-se ter uma visão geral sobre o perfil dos estudantes. Neste sentido, a pesquisa realizada buscou mapear as características dos estudantes e suas percepções e predisposição ao cooperativismo, que possibilitassem propor ações que contribuam com a formação de uma cooperativa de estudantes. Obteve-se o retorno de aproximadamente $10 \%$ dos estudantes do Campus.

No que tange a idade dos respondentes, 66,9\% possuem entre 18 a 24 anos, configurando um público bastante jovem, característica do perfil universitário, 24,2\% possuem entre 25 e 31 anos e apenas 8,9\% dos estudantes possuem 32 anos ou mais. Dos 269 respondentes, $65,8 \%$ foram do gênero Feminino, contra 34,2\% masculino, indicando um maior interesse do público feminino sobre o tema cooperativismo e maior pré-disposição para participar da pesquisa. Quanto ao estado civil, 73,6\% se declararam solteiros, $16 \%$ em união estável e 9,7\% são casados.

No que se refere a ocupação dos respondentes, 49,07\% declaram-se apenas estudantes, $34,57 \%$ alegam ser, além de estudantes, funcionários de empresas privadas, apenas 4,46\% são funcionários públicos, os 11,9\% restantes exercem as mais diversas atividades além do estudo. Os respondentes consideram que sua renda é proveniente de atividade econômica remunerada em, $54,6 \%$ dos casos $22,3 \%$ possui renda em regime de economia familiar e $14,1 \%$ possui renda oriunda de auxílio estudantil.

Os estudantes de Administração, um dos cursos com o maior número de alunos do Campus, corresponderam a 44,6\% dos respondentes, seguido pelo curso de Pedagogia com $7,4 \%$, História com 7,1\%, Geografia com 6,7\%, Enfermagem com 6,3\%, Letras com 5,2\%, Matemática com 4,5\%, Ciências Sociais e Ciência da Computação com 4,1\% cada, Agronomia com $3,7 \%$, os demais cursos somam juntos, $6,3 \%$ dos respondentes.

\section{Percepção e conhecimento dos estudantes sobre o cooperativismo}

Nesta seção, discute-se os resultados encontrados ao que tange o conhecimento dos estudantes a respeito de questões inerentes ao cooperativismo.

Ao questionar os estudantes da UFFS a respeito de algumas características que se enquadram ao seu perfil, no Gráfico 01, percebe-se que a maioria do público estudado se 
Revista Cadernos de Economia

Universidade Comunitária da Região de Chapecó - Unochapecó

identifica com as afirmativas referentes a compartilhamento, iniciativa e desejo de mudança e divisão de tarefas. Percebe-se que, há menor aderência ás características de baixo envolvimento com causas sociais, confiança no próximo e individualismo. A pergunta envolvia 6 afirmativas, da qual, quatro referiam-se a questões importantes para o bom funcionamento de uma cooperativa, e duas questões que prejudicam o cooperativismo. Atenta-se ao indicador de confiança no próximo, na qual, a afirmativa diz respeito a confiança que o estudante tem com relação ao trabalho de outras pessoas. Encontra-se que o perfil dos respondentes deixa claro um certo nível de desconfiança quanto às relações de trabalho, fator este, que pode dificultar um processo de cooperação.

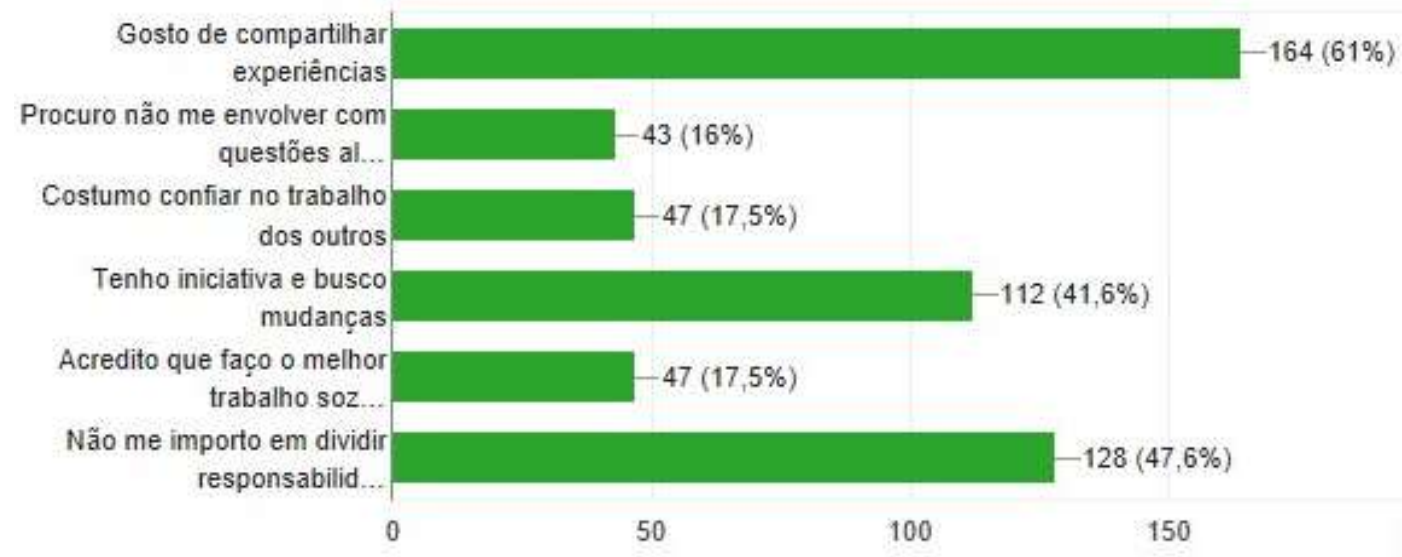

Gráfico 01 - Características de perfil

Fonte: Dados primários, 2018.

O Gráfico 2 apresenta, uma autoavaliação do estudante sobre o seu nível de conhecimento relativo ao cooperativismo. Através da utilização de uma escala Likert, sugeriuse ao respondente que avaliasse o seu conhecimento de 1 a 5 , em que, 1 significa pouco e 5 expressa muito. 
Revista Cadernos de Economia

Universidade Comunitária da Região de Chapecó - Unochapecó

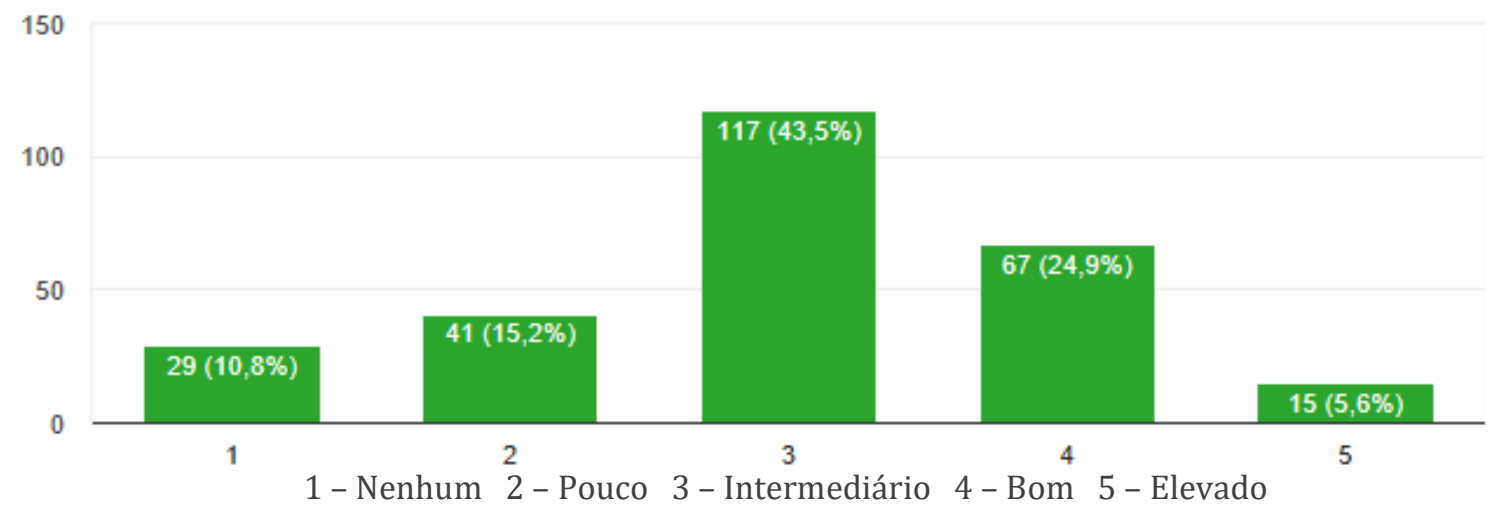

Gráfico 1 - Nível de conhecimento sobre o cooperativismo

Fonte: Dados primários, 2018.

Em números favoráveis, $24,9 \%$ dos estudantes avaliam ter um bom conhecimento, 43,5\% julgam ter um conhecimento intermediário, em que o estudante possui uma visão mais generalista do tema, não sendo um conhecimento fundamentado.

Buscou-se compreender a concepção sobre a participação das cooperativas na sociedade, levando em conta o princípio da preocupação com a sociedade. Dessa forma, 20,1\% dos respondentes consideram o cooperativismo como algo bastante positivo, 30,9\% dos respondentes analisam como sendo bom e 35,3\% percebem o cooperativismo com algo neutro. Apesar da maioria considerável de respondentes considerar o cooperativismo como algo positivo, existe um grupo de $11,2 \%$ dos estudantes que consideram o movimento como algo ruim e $2,6 \%$ muito ruim.

O entendimento dos princípios cooperativistas é fundamental para a compreensão do cooperativismo em sua essência. Desse modo, buscou-se apurar o conhecimento dos estudantes quanto aos sete princípios cooperativistas. Dessa forma, 32,7\% dos entrevistados relatam não conhecer os princípios cooperativistas, $17,8 \%$ consideram ter pouco conhecimento, 21,6\% acreditam conhecer alguma coisa, 16\% alegam possuir um bom conhecimento sobre os princípios e 11,9\% consideram conhecer os sete princípios de maneira mais aprofundada.

A estrutura societária de uma cooperativa é desconhecida por $27,1 \%$ dos estudantes, $20,8 \%$ consideram conhecer pouco, 22,3\% classificam como neutro, havendo um conhecimento superficial do assunto. Obteve-se 19,3\% dos estudantes alegando terem um bom conhecimento e $10,4 \%$ acreditam ter um conhecimento aprofundado. De maneira geral, o conhecimento sobre a estrutura societária das cooperativas ainda precisa ser discutido e estudado por grande parte dos estudantes. 
As sobras de uma cooperativa referem-se basicamente ao lucro da cooperativa, a diferença é que o lucro se refere a remuneração do capital investido, e as sobras se apresentam como o excedente da prestação de serviços da organização, dividido entre seus associados através da ajuda mútua. $\mathrm{O}$ conhecimento dos estudantes a respeito das sobras se demonstra bastante limitado, pois, em 30,1\% dos estudantes relatam não saber ao que se referem sobras, $18,6 \%$ apresentam conhecer pouco, $19 \%$ consideram conhecer razoavelmente, outros 19\% dizem ter um bom conhecimento sobre o assunto e apenas 13,4\% realmente conhecem o que são sobras e qual a sua finalidade.

A autogestão é um tema conhecido por 10,4\% dos respondentes, $21,6 \%$ consideram ter um bom conhecimento sobre o assunto, 26\% consideram ter uma breve noção, 24,9\% sabem pouco e $17,1 \%$ não possuem conhecimento sobre a autogestão. Em linhas gerais, $68 \%$ dos estudantes possuem baixo conhecimento sobre autogestão, sendo um dos princípios cooperativistas mais importantes para uma estrutura cooperativa.

O cooperativismo é um movimento que se destaca pelo envolvimento mútuo dos seus associados, por isso foi perguntado aos estudantes sobre o nível de percepção da sua rede de relacionamento quanto ao cooperativismo. Neste sentido, o cooperativismo se apresenta como algo muito bom, em $25,3 \%$ das respostas, bom para $32 \%$ e algo mediano para $30,5 \%$ dos respondentes. Para 7,8\% dos respondentes, o cooperativismo significa algo ruim e para 4,5\% dos casos se apresenta como algo muito ruim.

\section{Pré-disposição à cooperação na UFFS}

Através do questionário aplicado aos estudantes da UFFS Campus Chapecó, pode-se perceber alguns aspectos importantes para a definição da viabilidade de uma cooperativa de estudantes no Campus. Os fatores relacionados, buscam traçar alguns direcionadores para a criação e a manutenção de uma cooperativa de estudantes na UFFS.

O nível de interesse dos estudantes em se tornar associados de uma possível cooperativa de estudantes, se apresenta como favorável considerando que, 19,3\% dos respondentes possuem grande interesse em se associar, 32,3\% apresentam um bom nível de interesse em associação, $27,5 \%$ possuem algum tipo de interesse, no grupo intermediário, fazem parte as pessoas que se tornariam associadas a médio ou longo prazos, percebendo a atuação da cooperativa e seus resultados. Por fim, 11,2\% dos respondentes, apresentam pouco interesse em ser cooperado e $9,7 \%$ não estariam dispostos a se associar. 
O questionamento feito aos estudantes quanto ao retorno esperado ao associar-se a uma cooperativa, foi realizado por meio de uma pergunta na qual o respondente poderia escolher mais de uma alternativa. A perspectiva de retribuição está galgada no interesse dos estudantes quanto ao acesso facilitado a produtos e serviços voltados para os estudantes, 59,5\% dos estudantes preferem esse tipo de retorno. Outra expectativa para 58,4\% dos respondentes se deve ao fato de desenvolver novas habilidades e competências, fatores essenciais hoje, para o mundo do trabalho. Neste sentido, além de aprender com o próximo, os estudantes também pontuam, em 49,1\% dos casos, o compartilhamento de seu conhecimento.

Para 46,8\% dos respondentes, o retorno financeiro é uma possibilidade, vale destacar que, caso concretizem-se as expectativas anteriormente citadas, o retorno financeiro torna-se o resultado do esforço conjunto. Torna-se possível considerar ainda, que os respondentes que afirmam buscar retorno financeiro, podem estar partindo de uma ideia de que a cooperativa vá distribuir valores em moeda para seus associados, contudo, vale destacar que o retorno financeiro pode se apresentar como descontos, no consumo de produtos e/ou serviços da cooperativa, retorno da cota capital em forma de benefícios, entre outras diversas possibilidades, além da distribuição de sobras em espécie.

Uma provável cooperativa estudantil na UFFS Campus Chapecó, deveria desenvolver eventos com cerne a educação cooperativista, podendo também, caso necessário, fazê-los como forma de angariar fundos para a sua estruturação. Entre os estudantes que responderam à pesquisa, somados os percentuais, $56,1 \%$ teriam grande interesse em estar participando de algum evento promovido por uma cooperativa de estudantes, $29 \%$ se apresentam como indiferentes, público este que participaria, dependendo dos eventos disponibilizados. Por fim, $14,8 \%$ dos respondentes teriam baixo ou nenhum interesse em participar de eventos promovidos pela cooperativa.

O cooperativismo encontra na participação efetiva de seus associados um desafio a ser contornado. A pesquisa revela que $30,1 \%$ dos respondentes não possuem interesse em fazer parte da diretoria da cooperativa, 19,3\% possuem pouco interesse, 22,7\% são indiferentes. Outros $15,6 \%$ dos respondentes teriam um bom interesse em participar da diretoria e 12,3\% teriam grande interesse em participar. Conclui-se que, poucas pessoas estão realmente engajadas com a melhoria das condições dos estudantes, seja talvez, pelo receio em dirigir uma instituição burocrática, seja pela falta de conhecimento e experiências na área do cooperativismo. 
O dado anterior revelou que $30,1 \%$ dos respondentes não teria interesse de fazer parte da diretoria de uma cooperativa, pode-se perceber com a pesquisa que $26 \%$ dos estudantes revelam não ter tempo para participar das atividades de uma cooperativa. Ao fazer uma análise com os dados apresentados, cerca de $56 \%$ dos respondentes que afirmam não ter interesse em fazer parte da diretoria de uma cooperativa, não possuem tempo para exercer alguma atividade diretiva. Em contrapartida, 13\% afirmam ter de 1 a 4 horas disponíveis, mas não possuem interesse em gerir uma cooperativa.

Como questão estratégica para a constituição de uma cooperativa, buscou-se saber qual era a sua disposição financeira para a aquisição de cotas-capitais da cooperativa e assim integralizar o seu capital e poder atuar no âmbito do seu objetivo de constituição. De acordo com a pesquisa, a menor parcela dos estudantes, 14,5\% não disponham de recursos financeiros para constituir o capital da cooperativa. A maior parcela, 28,3\% teriam de $\mathrm{R} \$ 10,00$ a $\mathrm{R} \$ 30,00$, $17,5 \%$ disponibilizariam de $\mathrm{R} \$ 30,00$ a $\mathrm{R} \$ 60,00,20,4 \%$ teriam de $\mathrm{R} \$ 60,00$ a $\mathrm{R} \$ 100,00$ e $19,3 \%$ teriam mais de $\mathrm{R} \$ 100,00$ para contribuir com o capital da cooperativa.

Um dos principais indicadores da viabilidade de uma cooperativa de estudantes na UFFS, a propensão ao consumo de produtos e/ou serviços oferecidos pela organização. $\mathrm{O}$ resultado foi extremamente significativo, uma vez que $28,6 \%$ dos estudantes afirmam que consumiriam. Observa-se que $34,9 \%$ possuem grande interesse em consumir, e $25,7 \%$ consumiriam indiferentemente de ser cooperativa ou não. Apenas 10,4\% possivelmente não consumiriam e apenas $0,4 \%$ afirmam que não consumiriam.

A pesquisa teve como objetivo ainda, conhecer as principais necessidades de consumo dos estudantes da UFFS. A atividade apontada por $71,7 \%$ dos respondentes, é a Gestão, principalmente do Xerox e do Restaurante Universitário. Outra área bastante expressiva é a da Alimentação, da qual 65,4\% consideram que a Cantina e/ou Food Trucks poderiam ser de uma cooperativa de estudantes. Os estudantes consideram a área de Consumo interessante em 60,2\% das respostas, podendo comercializar itens dos cursos, como moletons, camisetas, canecas, entre uma linha de diversos itens. Pode-se destacar ainda áreas como a Saúde com $56,1 \%$ e Papelaria 55\% que também tiveram um interesse bastante significativo por parte dos estudantes.

Até o momento, discutiram-se questões fechadas e com alternativas restritas. Com vistas a obter um maior entendimento da opinião dos estudantes quanto a criação e atuação de uma cooperativa, disponibilizou-se no final do formulário, uma questão aberta, na qual, o respondente teria liberdade para expressar o seu sentimento ou opinião quanto a criação de uma cooperativa estudantil no Campus Chapecó da Universidade Federal da Fronteira Sul. 
Obteve-se 10 colaborações, na qual expressam diferentes opiniões. Trata-se os respondentes, como Estudante e $\mathrm{X}$ o número da ordem de sua resposta. Ressalta-se que todas as respostas são anônimas e que todas as contribuições foram importantes para as conclusões do trabalho.

O Estudante 1 destaca "Muito legal a ideia, difícil achar serviços que eu não consumiria nesta lista", percebe-se a propensão do mesmo ao consumo. O Estudante 2 possui a ideia de que "Uma cooperativa só e considerada boa quando tudo está correndo bem, mas lembrem-se você é associado na alegria e na tristeza". O Estudante 2 salienta o fato de que, em caso de sobras, a cooperativa pode dividir entre os associados, ou aplicar em seu crescimento, e, em caso de prejuízos, os mesmos também são arcados pelos seus associados. De fato, a mesma questão ocorre em qualquer organização, em qualquer tipo de sociedade, mas, da mesma forma como se divide o capital para a constituição da cooperativa, se dividem também os prejuízos que possa por vir a acontecer.

O Estudante 3 preocupa-se principalmente na burocracia para a constituição de uma cooperativa, e também na problematização da necessidade de alguns alunos em ter que realizar "manobras" para a sua permanência na universidade. Outro ponto abordado pelo estudante é a sua preocupação com o impedimento do livre comércio e de trocas entre os estudantes. Partese do pressuposto que uma cooperativa de estudantes não deveria ser criada para satisfazer a necessidade de um grupo restrito de alunos, como destacado pelo Estudante 3 quando questiona a necessidade da criação de uma cooperativa para que um estudante possa "vender alguns livros para pagar o Restaurante Universitário ou o ônibus". O fato é que, uma cooperativa estudantil deve se consolidar para satisfazer o anseio da maioria dos estudantes. A pesquisa realizada comprova que os anseios dos estudantes da UFFS não estão neste tipo de atividade, mas sim, na prestação de serviços que possam melhorar as condições de todo e qualquer estudante, associado ou não. O Estudante 3 ainda salienta a necessidade de tempo e informação para o funcionamento da cooperativa, o tempo pode ser revertido com escalas de trabalho e a colaboração de voluntários, e as informações e conhecimento necessários para constituir uma cooperativa, podem ser adquiridos por meio da colaboração de pessoas que atuam na área.

O Estudante 4 destaca a necessidade de, em caso da criação de uma cooperativa que preste serviços na área da alimentação, de que a mesma ofereça "Produtos livres de glúten e lactose nas cantinas". A preocupação do estudante provém da necessidade de boa parcela da população em estar consumindo produtos livres de glúten e lactose, necessidade esta, em parte, 
não atendida pelas empresas que atuam com a comercialização de alimentos na cantina e nos Food Trucks atuantes na universidade.

O Estudante 5 relata a seguinte preocupação, "Concluo o curso neste ano, os ex-alunos teriam a opção de participar da cooperativa? ". O público que uma possível cooperativa pudesse atender, deve ser delimitado na criação de seu Estatuto Social, de fato, quanto maior o quadro social da cooperativa, maior é o capital integralizado pela mesma, e maiores serão as possibilidades e abrangência, podendo não se restringir apenas a estudantes.

O Estudante 6 destaca que "Cooperativas devem ser feitas por um interesse comum". Como se pode perceber, os interesses dos estudantes estão postos na pesquisa anteriormente apresentada, em que se percebe que os estudantes buscam, acima de defesa econômica, a sua defesa cultural e social, através de serviços variados que possibilitem a viabilidade de uma organização cooperativista.

Como destaca o Estudante 7, "Julgo interessante e possível a ideia", neste sentido também, o Estudante 8 corrobora com a consideração de que "caso venha ser implementada a cooperativa serei grande apoiadora e consumidora".

\section{Estratégias de ação para a constituição de uma cooperativa na UFFS}

Munido de um arsenal teórico e principalmente prático e experiencial, consideram-se algumas questões relevantes para a constituição de uma cooperativa na UFFS Campus Chapecó. Através da pesquisa realizada com os acadêmicos do Campus e das experiências apresentadas, podem-se destacar algumas ações que possam contribuir com a constituição e consolidação de uma cooperativa de estudantes na universidade.

Inicialmente, destaca-se na pesquisa realizada, pontos caracterizando a desconfiança dos estudantes com relação ao trabalho dos colegas, característica hoje, muito presente na sociedade individualista. Tal fato, só pode ser revertido através da convivência e do conhecimento do grupo e da instituição pautada, caso contrário, uma cooperativa que se constitui com base na desconfiança mútua e no conflito de interesses, se vencer o processo de constituição, não vence o processo de consolidação. É preciso chegar a um grupo de interesses afins, pautados em uma relação de respeito e dedicação de todos.

O processo proposto não parece fácil, mas destacam-se medidas que podem auxiliar. Medidas como a realização de reuniões periódicas entre um possível grupo fundador, e também com a comunidade acadêmica da universidade, na qual se discute a razão de existir da 
cooperativa, as principais demandas e resultados esperados, além de pensar em soluções e a divisão de tarefas para a realização de cada passo na constituição da cooperativa. Outro importante fator para gerar confiança é a transparência nas ações e atitudes.

Existe uma grande lacuna de conhecimento no que diz respeito ao cooperativismo na universidade. Embora seja uma região cujos traços de desenvolvimento possuem forte contribuição cooperativista, a educação cooperativista parece não estar colaborando com a disseminação de uma cultura cooperativista. Dessa forma, o conhecimento sobre o tema cooperativismo, sobre os princípios cooperativistas, da estrutura societal e do destino das sobras de uma cooperativa, precisam ser amplamente discutidas e, principalmente, disseminadas muito antes de se pensar em formar uma estrutura burocrática. Tendo em vista a viabilidade de uma cooperativa, os fatores mencionados acima, merecem destaque em palestras, seminários, rodas de conversa, em cartazes e materiais de divulgação diversos, promovendo a conscientização dos estudantes, bem como o engajamento ou não, dos mesmos para constituírem a cooperativa.

Tanto a percepção dos estudantes, quanto a da sua rede de relacionamento, demonstram que o cooperativismo exerce um papel importante na sociedade e um impacto positivo na vida das pessoas no contexto regional. Dessa forma, os bons exemplos de cooperativas devem entrar em pauta. Neste sentido, estudantes devem expor exemplos de boas práticas cooperativistas e também das práticas ruins, evitando que a mesma possa vir a ocorrer na cooperativa, através de rodas de conversa, ou até mesmo, uma urna que possa armazenar opiniões e exemplos de forma prática e anônima, permitindo a colaboração dos estudantes tanto na constituição, quanto na sua manutenção.

O alicerçamento de uma cooperativa de estudantes está na manutenção de seus associados e também na prospecção de novos cooperados, mantendo a viabilidade da cooperativa ao longo do tempo. Neste sentido, recomenda-se que seja realizado um planejamento bem estruturado, visando agregar serviços que possibilitem vantagens reais aos seus associados, como por exemplo, programas de pontuação por consumo, retornando ao associado em forma de benefícios proporcionais ao seu consumo na cooperativa. Outra forma de atrair novos cooperados seria através de eventos educativos e também campanhas de marketing na universidade.

Outra situação observada e que necessitaria de ações para o seu desenvolvimento, se trata do número reduzido de estudantes interessados em fazer parte da diretoria da cooperativa. Uma das ações mais frequentes e que poderiam ser tomadas nos primeiros anos da cooperativa, 
Revista Cadernos de Economia

Universidade Comunitária da Região de Chapecó - Unochapecó

até a mesma despertar a participação efetiva dos alunos, se refere a uma renovação parcial da diretoria a cada nova eleição. Assim como se sugere o tempo de gestão de cada pleito de dois anos, como é o caso da maioria das cooperativas estudantis apresentadas.

Com relação ás atividades e ramos de atuação, tomando por consideração o desenvolvimento de todo um trabalho de conscientização e de educação cooperativista, uma cooperativa estudantil poderia iniciar as suas atividades gerindo a central de cópias da universidade, ou a cantina da mesma, fazendo com que se construísse conhecimento e capital para projetos maiores. Destaca-se também que, apesar da viabilidade mercadológica de tal atividade, faz-se necessário também um estudo de viabilidade econômica e financeira, para assegurar que o investimento dos associados terá retornos consideráveis.

\begin{tabular}{|c|c|c|c|c|c|c|}
\hline O que? & Por quê? & Quem? & Quando? & Onde? & Como? & Quanto? \\
\hline $\begin{array}{l}\text { Construir a } \\
\text { confiança } \\
\text { da equipe }\end{array}$ & $\begin{array}{l}\text { Sem confiança } \\
\text { mútua não existe } \\
\text { cooperação }\end{array}$ & $\begin{array}{l}\text { Grupo } \\
\text { fundador e } \\
\text { estudantes } \\
\text { da UFFS }\end{array}$ & $\begin{array}{c}\text { Já nos } \\
\text { primeiros } \\
\text { encontros }\end{array}$ & $\mathrm{Na}$ UFFS & $\begin{array}{c}\text { Reuniões periódicas e } \\
\text { transparência nas ações } \\
\text { e atitudes }\end{array}$ & $\begin{array}{l}\text { Não } \\
\text { mensu- } \\
\text { rável }\end{array}$ \\
\hline $\begin{array}{c}\text { Gerar } \\
\text { conhecimen } \\
\text { to sobre } \\
\text { cooperativis } \\
\text { mo }\end{array}$ & $\begin{array}{c}\text { Para que os } \\
\text { estudantes } \\
\text { conheçam uma } \\
\text { cooperativa e a } \\
\text { sua importância }\end{array}$ & $\begin{array}{l}\text { Grupo } \\
\text { fundador, } \\
\text { professores }\end{array}$ & $\begin{array}{l}\text { Qualquer } \\
\text { momento }\end{array}$ & $\mathrm{Na}$ UFFS & $\begin{array}{l}\text { Palestras, seminários, } \\
\text { rodas de conversa, } \\
\text { cartazes e materiais de } \\
\text { divulgação diversos }\end{array}$ & $\begin{array}{l}\text { Não } \\
\text { mensu- } \\
\text { rável }\end{array}$ \\
\hline $\begin{array}{l}\text { Apresentaç } \\
\text { ão de } \\
\text { exemplos }\end{array}$ & $\begin{array}{l}\text { Ampliar o campo } \\
\text { de conhecimento } \\
\text { e aprender com as } \\
\text { experiências }\end{array}$ & $\begin{array}{l}\text { Dirigentes } \\
\text { ou ex } \\
\text { dirigentes } \\
\text { de } \\
\text { cooperativ } \\
\text { as }\end{array}$ & $\begin{array}{l}\text { Antes da } \\
\text { constituição } \\
\text { da } \\
\text { cooperativa } \\
\text { ou qualquer } \\
\text { momento }\end{array}$ & $\begin{array}{l}\text { Na UFFS } \\
\text { ou em } \\
\text { visita a } \\
\text { coope- } \\
\text { rativas }\end{array}$ & $\begin{array}{l}\text { Debates, rodas de } \\
\text { conversas, urnas de } \\
\text { opinião }\end{array}$ & $\begin{array}{l}\text { Não } \\
\text { mensu- } \\
\text { rável }\end{array}$ \\
\hline $\begin{array}{l}\text { Definir o } \\
\text { ramo de } \\
\text { atuação }\end{array}$ & $\begin{array}{l}\text { Demonstrar o } \\
\text { objetivo da } \\
\text { existência da } \\
\text { cooperativa e } \\
\text { definir o seu } \\
\text { planejamento }\end{array}$ & $\begin{array}{l}\text { Grupo } \\
\text { fundador e } \\
\text { estudantes } \\
\text { da UFFS }\end{array}$ & $\begin{array}{c}\text { Antes da } \\
\text { constituição } \\
\text { da } \\
\text { cooperativa }\end{array}$ & $\mathrm{Na}$ UFFS & $\begin{array}{l}\text { Por meio de reuniões } \\
\text { definindo opções e } \\
\text { assembleia geral } \\
\text { apresentando-as aos } \\
\text { estudantes }\end{array}$ & $\begin{array}{l}\text { Não } \\
\text { mensu- } \\
\text { rável }\end{array}$ \\
\hline $\begin{array}{l}\text { Prospecção } \\
\text { e } \\
\text { manutenção } \\
\text { de } \\
\text { associados }\end{array}$ & $\begin{array}{l}\text { Manutenção e } \\
\text { expansão do } \\
\text { quadro social }\end{array}$ & $\begin{array}{l}\text { Diretoria e } \\
\text { cooperados }\end{array}$ & Diariamente & $\mathrm{Na}$ UFFS & $\begin{array}{c}\text { Programas que } \\
\text { demonstrem vantagens } \\
\text { reais, eventos } \\
\text { educativos, campanhas } \\
\text { de marketing }\end{array}$ & $\begin{array}{l}\text { Não } \\
\text { mensu- } \\
\text { rável }\end{array}$ \\
\hline $\begin{array}{l}\text { Constituiçã } \\
\text { o da } \\
\text { cooperativa }\end{array}$ & $\begin{array}{l}\text { Garantir a } \\
\text { legalidade da } \\
\text { instituição }\end{array}$ & $\begin{array}{l}\text { Grupo } \\
\text { fundador e } \\
\text { estudantes } \\
\text { da UFFS }\end{array}$ & $\begin{array}{c}\text { Durante o } \\
\text { processo de } \\
\text { constituição } \\
\text { da } \\
\text { cooperativa }\end{array}$ & $\begin{array}{l}\text { Na UFFS } \\
\text { ou na } \\
\text { cidade de } \\
\text { Chapecó }\end{array}$ & $\begin{array}{c}\text { Realizar a assembleia } \\
\text { de constituição; } \\
\text { Permissões para } \\
\text { atuação junto a UFFS; } \\
\text { Registro na Junta } \\
\text { Comercial; } \\
\text { Registro na OCESC; }\end{array}$ & $\begin{array}{l}\text { Passível } \\
\text { de } \\
\text { pesquisa }\end{array}$ \\
\hline $\begin{array}{c}\text { Aumento do } \\
\text { interesse em } \\
\text { ser } \\
\text { dirigente }\end{array}$ & $\begin{array}{c}\text { Evitar a } \\
\text { dissolução por } \\
\text { falta de } \\
\text { candidatos a } \\
\text { diretoria }\end{array}$ & $\begin{array}{l}\text { Diretoria e } \\
\text { cooperados }\end{array}$ & Diariamente & $\mathrm{Na}$ UFFS & $\begin{array}{l}\text { Renovação parcial da } \\
\text { diretoria da cooperativa }\end{array}$ & $\begin{array}{l}\text { Não } \\
\text { mensu- } \\
\text { rável }\end{array}$ \\
\hline
\end{tabular}


Revista Cadernos de Economia

Universidade Comunitária da Região de Chapecó -Unochapecó

\begin{tabular}{|c|c|c|c|c|c|c|}
\hline $\begin{array}{c}\text { Definição } \\
\text { das } \\
\text { atividades } \\
\text { da } \\
\text { cooperativa }\end{array}$ & $\begin{array}{c}\text { Evitar } \\
\text { investimentos que } \\
\text { levem a prejuízos } \\
\text { consideráveis }\end{array}$ & $\begin{array}{l}\text { Grupo } \\
\text { fundador e } \\
\text { estudantes } \\
\text { da UFFS }\end{array}$ & $\begin{array}{l}\text { Já nos } \\
\text { primeiros } \\
\text { encontros }\end{array}$ & $\mathrm{Na}$ UFFS & $\begin{array}{l}\text { Estudo de viabilidade } \\
\text { econômica e financeira }\end{array}$ & $\begin{array}{l}\text { Não } \\
\text { mensu- } \\
\text { rável }\end{array}$ \\
\hline $\begin{array}{l}\text { Realizar } \\
\text { escalas de } \\
\text { trabalho }\end{array}$ & $\begin{array}{l}\text { Evitar sobrecarga } \\
\text { de trabalho e } \\
\text { esforço por parte de } \\
\text { alguns estudantes }\end{array}$ & $\begin{array}{l}\text { Grupo } \\
\text { fundador/ } \\
\text { diretoria }\end{array}$ & $\begin{array}{c}\text { Já nos } \\
\text { primeiros } \\
\text { encontros, } \\
\text { diariamente }\end{array}$ & $\mathrm{Na}$ UFFS & $\begin{array}{l}\text { Programação semanal } \\
\text { em escala de trabalho e } \\
\text { divisão de tarefas }\end{array}$ & $\begin{array}{l}\text { Não } \\
\text { mensu- } \\
\text { rável }\end{array}$ \\
\hline $\begin{array}{c}\text { Valor } \\
\text { acessível } \\
\text { para } \\
\text { associação }\end{array}$ & $\begin{array}{l}\text { Ganhar maior } \\
\text { número de adesões } \\
\text { e respeitar as } \\
\text { condições } \\
\text { econômicas dos } \\
\text { estudantes }\end{array}$ & $\begin{array}{l}\text { Grupo } \\
\text { fundador/ } \\
\text { diretoria }\end{array}$ & $\begin{array}{c}\mathrm{Na} \\
\text { constituição } \\
\text { da } \\
\text { cooperativa }\end{array}$ & Na UFFS & $\begin{array}{l}\text { Cota-capital de } \mathrm{R} \$ \\
60,00 \text { com } \\
\text { possibilidade de } \\
\text { parcelamento }\end{array}$ & $\begin{array}{l}\text { Não } \\
\text { mensu- } \\
\text { rável }\end{array}$ \\
\hline
\end{tabular}

Quadro 03 - Estratégias de ação para constituir e consolidar uma cooperativa estudantil

Fonte: Elaborado pelo autor, 2018.

Outro ponto importante está relacionado com as escalas de trabalho na cooperativa, da qual para que haja um bom funcionamento da mesma, e para que o trabalho não fique apenas nas mãos de alguns associados, deve-se pensar em uma programação semanal das escalas de trabalho, dividindo-se tarefas, de forma a atender os anseios dos cooperados e também dos consumidores. Esta ação, evitaria que o trabalho da cooperativa sobrecarregasse o tempo escasso de alguns dirigentes e associados, fazendo com que desistam por falta de engajamento da equipe.

Outro fator importante atrelado a sobrevivência da cooperativa, está no valor da cota capital para se tornar associado. A pesquisa apresentou que existe uma disposição significativa de estudantes que contribuiriam com mais de $\mathrm{R} \$ 100,00$ para constituir a sua cota-capital, mas com vistas a atingir um público maior, deve-se considerar nos estudantes em situação de vulnerabilidade econômica, que por ventura não teriam esse valor. Por meio da pesquisa, pode-se definir que um valor bastante significativo para a construção do capital da cooperativa seria algo próximo de $\mathrm{R} \$ 60,00$ em cota-capital, podendo este valor, ser integralizado em até três vezes.

Como se pôde perceber nas respostas dos questionários, existe um grupo expressivo de estudantes que possuem expectativas elevadas sobre o cooperativismo, destaca-se que uma cooperativa de estudantes é possível, desde que ela respeite os ideais cooperativistas e ofereça inovação aos seus cooperados. Resume-se o plano de ações no Quadro 03, elaborado com a metodologia $5 \mathrm{~W} 2 \mathrm{H}$, neste plano, apresenta-se as medidas anteriormente citadas como forma de definir estratégias para a constituição e consolidação de uma cooperativa de estudantes na UFFS Campus Chapecó. 
O plano de ação pode ser utilizado como um direcionador estratégico da cooperativa, bem como norteador das ações de um grupo fundador, evitando assim, o desgaste pela repetição de erros cometidos no passado e possibilitando a consolidação de uma cooperativa bem estruturada. Destaca-se ainda, a importância dessas ações no desenvolvimento da educação e da cultura cooperativista, promovendo acima de tudo a integração, a solidariedade e a construção de conhecimento.

\section{CONSIDERAÇÕES FINAIS}

Abordando o tema do cooperativismo estudantil, identificou-se certa deficiência de estudos, o tema não possui um quantitativo considerável de publicações, mas apresenta alguns estudos interessantes na área.

O referido trabalho teve como objetivo geral propor estratégias para fomentar o comportamento cooperativista para a constituição de uma cooperativa de estudantes na UFFS Campus Chapecó/SC. Buscou-se inicialmente, apresentar experiências de cooperativas estudantis, analisando alguns fatores motivadores para a sua constituição, suas dificuldades e aspectos voltados a participação dos associados nos processos de autogestão e de operacionalização das atividades da cooperativa.

Entrevistou-se representantes de seis cooperativas, sendo três cooperativas escola do estado de Santa Catarina e três cooperativas do estado do Rio Grande do Sul, sendo uma delas, a maior cooperativa da américa latina em seu ramo de atuação. Outra vertente do estudo buscou analisar a viabilidade mercadológica para a constituição de uma cooperativa de estudantes na UFFS Campus Chapecó, obtendo-se assim, a colaboração espontânea de 269 estudantes.

Inicialmente percebeu-se que, como é de característica do público universitário, os estudantes e potenciais associados de uma cooperativa, são bastante jovens. Os respondentes em sua grande maioria são do gênero feminino, estudantes e funcionários de empresas privadas, tendo assim, uma atividade econômica remunerada. Das características de perfil, todos os estudantes questionados são propensos a cooperação, com exceção da confiança no trabalho de outras pessoas, fator este que deve ser trabalhado.

O nível geral de conhecimento sobre o cooperativismo e suas principais características é baixo e a percepção dos estudantes e de sua rede de relacionamentos sobre o tema é bastante 
Revista Cadernos de Economia

Universidade Comunitária da Região de Chapecó -Unochapecó

positiva. Torna-se bastante evidente também, que ao se tornarem associados de uma cooperativa, os estudantes busquem por ter acesso facilitado a produtos e serviços estudantis existe um grande interesse por parte dos estudantes, em fazer parte do quadro social de uma cooperativa, e a predisposição em fazer parte de eventos promovidos por uma cooperativa de estudantes.

O interesse reduz consideravelmente quando se trata de fazer parte da diretoria, o motivo pode estar no fato dos estudantes terem pouco tempo disponível para atividades extraclasse e em algumas situações, não estarem dispostos a assumirem maiores responsabilidades. Pode-se observar que um valor considerável para cota-capital na cooperativa seria de $\mathrm{R} \$$ 60,00 , possibilitando a mesma, captar fundos para constituir a cooperativa e possibilitar o acesso a um público maior de estudantes. Nesta perspectiva, existe um grande interesse dos estudantes em consumir produtos e serviços de uma cooperativa no Campus da UFFS.

O trabalho objetivou ainda apontar estratégias a serem adotadas para a viabilização do processo de constituição de uma cooperativa de estudantes na UFFS. Essas medidas possuem a intenção de resolver uma série de problemas atreladas a questões sociais e operacionais, que por ventura atrapalhariam o processo de construção coletiva de uma cooperativa, como a geração do conhecimento sobre o cooperativismo na universidade, a definição das atividades e benefícios gerados para os associados por meio de estudo de viabilidade econômica e financeira, a prospecção de novos associados e o aumento do interesse por parte dos alunos em ser dirigente da cooperativa.

Considerando as experiências cooperativistas apresentadas e a pesquisa realizada com os estudantes, considera-se viável a constituição de uma cooperativa de estudantes na UFFS Campus Chapecó, desde que, a mesma, passe por um processo de construção coletiva, obedecendo os princípios cooperativistas e, principalmente, passe por um estudo de viabilidade econômica e financeira, que comprove a sua consolidação no tempo. Como indicações para estudos futuros, considera-se tratar um plano de viabilidade econômica e financeira para uma cooperativa de estudantes na UFFS, estudos voltados a relação entre as cooperativas escola e os CEDUPS do estado de Santa Catarina, a possibilidade da implantação de uma cooperativa descentralizada na universidade. 


\section{REFERÊNCIAS}

ANDRIOLI, A. I. Trabalho coletivo e educação: um estudo das práticas cooperativistas do PCE - Programa de Cooperativismo nas Escolas - Na região Fronteira Noroeste do Estado do Rio Grande do Sul. 2. Ed. - Ijuí: Editora Unijuí, 2007.

APPOLINÁRIO, F. Metodologia da ciência: filosofia e prática da pesquisa. São Paulo: Cengage Learning, 2011.

AZAMBUJA, L. R. Os valores da economia solidária. Sociologias, v. 21, n. 11, pp. 282317, jul/2009.

BIALOSKORSKI NETO, S. Economia e gestão de organizações cooperativas. ed. 2. São Paulo: Atlas. 2012.

Congresso. Horizontina: FAHOR, 2013. Disponível em:

<http://www.fahor.com.br/publicacoes/sief/2013/gestao_de_qualidade.pdf >. Acesso em: 22 mar. 2018.

SERVIÇO NACIONAL DE APRENDIZAGEM DO COOPERATIVISMO (SESCOOP/RS). Expressão do cooperativismo gaúcho. Porto Alegre: Sescoop/RS, v. 6, 2016. Disponível em: <http://www.sescooprs.coop.br/app/uploads/2017/07/sescooprsexpressao-cooperativismo-gaucho-2017.pdf>. Acesso em: 07 nov. 2017.

FRANTZ, W. Associativismo, cooperativismo e economia solidária. Ijuí: Editora Unijuí, 2012.

GERHARDT, T. E.; SILVEIRA, D. T. (Org.). Métodos de pesquisa. Porto Alegre: Editora da UFRGS, 2009.

LAGO, A.; SILVA, T. N da. Fatores condicionantes do desenvolvimento de relacionamentos intercooperativas no cooperativismo agropecuário. Porto Alegre: Sescoop/RS, 2011. 206 p.

MARCONI, M. de A.; LAKATOS, E. M. Técnicas de pesquisa: planejamento e execução de pesquisas, amostragens e técnicas de pesquisa, elaboração, análise e interpretação de dados. 7. ed. São Paulo: Atlas, 2011.

REISDORFER, V. K. Introdução ao cooperativismo. Santa Maria: Universidade Federal de Santa Maria, Colégio Politécnico, Rede e-Tec Brasil, 2014.

SILVA, A. da et al. Gestão da Qualidade: aplicação da ferramenta 5W2H como plano de ação para projeto de abertura de uma empresa. In: $3^{\text {a }}$ SIEF - Semana Internacional das Engenharias da FAHOR e $7^{\circ}$ Seminário Estadual de Engenharia Mecânica e Industrial.

SOUZA, A. C. de; FIALHO, F.; OTANI, N. TCC: Métodos e Técnicas. Florianópolis: Visual Books, 2007. 160 p.

VERGARA, S. C. Projetos e relatórios de pesquisa em administração. - 14. Ed. - São Paulo: Atlas, 2013. 